\title{
Finite-Time Current Tracking in Boost Converters by Using a Saturated Super-Twisting Algorithm
}

\author{
Juan-Eduardo Velázquez-Velázquez (D), Rosalba Galván-Guerra (i), \\ José-Antonio Ortega-Pérez $\mathbb{D}^{\mathbb{D}},{ }^{2}$ Yair Lozano-Hernández $\mathbb{D}^{3},{ }^{3}$ and Raúl Villafuerte-Segura $\mathbb{D}^{4}$ \\ ${ }^{1}$ Instituto Politécnico Nacional, Unidad Profesional Interdisciplinaria de Ingeniería Campus Hidalgo, San Agustin Tlaxiaca, \\ Hidalgo 42162, Mexico \\ ${ }^{2}$ Instituto Politécnico Nacional, Centro de Investigación y Desarrollo de Tecnología Digital, \\ Tijuana, Baja California 22435, Mexico \\ ${ }^{3}$ Instituto Politécnico Nacional, Escuela Superior de Ingeniería Mecánica y Eléctrica Unidad Zacatenco, Mexico, \\ CDMX 07738, Mexico \\ ${ }^{4}$ Universidad Autónoma del Estado de Hidalgo, Centro de Investigación en Tecnologías de Información y Sistemas, Pachuca, \\ Hidalgo 42184, Mexico \\ Correspondence should be addressed to Rosalba Galván-Guerra; rgalvang@ipn.mx
}

Received 27 May 2020; Revised 29 August 2020; Accepted 24 September 2020; Published 30 October 2020

Academic Editor: Ning Cai

Copyright (C) 2020 Juan-Eduardo Velázquez-Velázquez et al. This is an open access article distributed under the Creative Commons Attribution License, which permits unrestricted use, distribution, and reproduction in any medium, provided the original work is properly cited.

\begin{abstract}
The power converters are widely used in several industrial applications where it is necessary to obtain from a fixed voltage another one higher or lower than the original. In this paper, we focus on the DC-DC (direct current) boost converters, where to guarantee the desired voltage, an internal current tracking loop is usually used. However, this tracking cannot be assured in the presence of unknown load changes and external perturbations when traditional controller strategies are implemented. In this paper, an advanced control strategy is proposed to ensure the current tracking using a saturated super-twisting controller on the power converter. The finite-time current tracking of a DC-DC boost converter is assured in the presence of bounded Lipschitz perturbations composed by unknown load changes and exogenous signals. The proposed approach generates a continuous bounded control signal applied to the converter by using a sigma-delta modulator $(\Sigma \Delta M)$. The controller gains are tuned to obtain finitetime stabilization of the tracking error, while the control signal remains bounded. To illustrate the effectiveness of the proposed results, the controller is applied to a physical boost converter using the hardware implemented $(\Sigma \Delta M)$ and an STM32 Discovery development card. Besides, the controller is compared with a first-order sliding mode controller showing that for small sample times, the energy of the error signal is reduced.
\end{abstract}

\section{Introduction}

The DC-DC power converters are used in contemporary applications and have been widely investigated in the last three decades. They are the ideal candidates in several applications such as electric and hybrid vehicles, fuel cells, microgrids, and photovoltaic and renewable energy storage systems [1-7]. The natural operation of power converters requires that the control variable takes values from a discrete set. Several efforts to control power converters involving discrete components, integrated circuits, and/or pulse width modulation (PWM) have been reported in the literature [8-16], where schemes based on PI, passivity, adaptive backstepping, fuzzy logic, deadbeat, $\mathrm{H}$-infinity, or model predictive control are used.

In general, the main control objective of power converters is the voltage regulation. According to [17-20], this control problem can be solved by using a cascaded control structure with two loops: an inner current loop and an outer voltage loop. Traditionally, a simple PI compensator is applied to regulate the voltage and generate the current reference signal. Moreover, several applications require that 
the current follows a specific current profile [21-24]. It is worth to mention that the rate of the current is faster than the one of the output voltage, making necessary the design of fast strategies that guarantee the exact tracking of the current profile. Moreover, in practice, the load may vary depending on external factors affecting the tracking of the desired current [17, 25-27].

The effects of the unknown load changes can be seen as perturbations. The sliding mode controllers are well known by its ability to compensate theoretically exactly the matched uncertainties/perturbations $[18,28]$. The accuracy and structure of these controllers depend on the uncertainties/ disturbances considered and the relative degree of the sliding variable.

In the sliding mode framework, the first-order sliding mode (FOSM) control is widely used in the current control loop implementation $[17,29]$. This controller works in the on-off mode and allows compensating in finite-time bounded matched uncertainties/perturbations. However, if the commuting frequency is not high enough, it generates high-level chattering or ripple [20,29]. An alternative to this controller type is a super-twisting algorithm (STA) based controller [30,31]. This controller compensates Lipschitz uncertainties/perturbations by using continuous control signals, and the generated chattering is diminished in comparison with a FOSM $[32,33]$. However, it cannot guarantee that the generated control signal remains bounded, preventing its use in power converters. Recently, a saturated STA (SSTA) has been proposed in [34, 35], and it generates a bounded control signal, while it compensates in finite-time bounded Lipschitz uncertainties/perturbations.

Among the power converters, the boost converter is a nonminimum phase highly nonlinear system. This difficult the control design for the regulation or tracking of a reference voltage. The voltage tracking problem can be reformulated in terms of the current one, which makes the design of the inner current control loop crucial. In the literature, several strategies based on the FOSM have been designed for the boost converter. For example, [36] uses an adaptive controller guaranteeing asymptotic stability of the closed-loop system, while [27] proposes an adaptive backstepping control strategy considering the presence of a constant power load (CPL) and bounded external perturbations and parameter uncertainties. The closed-loop system's sensitivity function amplitude is reduced in [37] by using an optimized feedback control scheme. In [20], a control design procedure is given for DC-DC power converters with different control objectives, and the chattering is attenuated by using a harmonic cancellation method approach.

The aim of this paper is the design of the inner current control loop for boost converters. A tracking control strategy based on the SSTA is proposed to guarantee in finite-time a desired inductor current profile in the presence of Lipschitz and bounded uncertainties/perturbations conformed by unknown changes in the load, model uncertainties, and external perturbations. To illustrate the benefits of the proposed approach, the SSTA controller is compared with a FOSM controller using a chattering analysis via simulation.
This comparison shows that the use of a continuous sliding mode control strategy attenuates the energy of the error signal. An efficiency analysis is also performed in simulation, and the SSTA controller is compared in terms of power efficiency with a conventional LQ controller and a FOSM one. This analysis reveals that the use of a variable structure controller improves considerably the efficiency of the boost converter. In addition, the obtained results are implemented in a boost converter prototype to illustrate the applicability of the proposed methodology.

This paper is organized as follows. Some preliminaries results, the test setup, and the problem formulation are described in Section 2. The controller design that stabilize in finite-time the tracking inductor current error is given in Section 3. Section 4 gives the simulation results and the performed analysis. The implementation is detailed in Section 5. Finally, Section 6 concludes the paper.

\section{Preliminaries and Problem Formulation}

2.1. Ideal Boost Converter. The boost power converter [38] was selected as the test setup. This converter is a voltage elevator capable to increase the capacitor voltage $v$ over the input voltage $E$ of the converter. In Figure 1, a schematic of this converter is shown, assuming ideal elements.

Due to the transistor $Q$, the converter commutes between two states $u(t)=1$ and $u(t)=0$, that denotes the onoff state of the transistor. The two subsystems are depicted in Figures 2 and 3 .

Let $i$ be the inductor current and $v$ the capacitor voltage, and the mathematical model of the converter [38] is given below.

(i) If $u(t)=1$

$$
\begin{array}{r}
L \dot{i}(t)=E, \\
C \dot{v}(t)=-\frac{v(t)}{R} .
\end{array}
$$

(ii) If $u(t)=0$

$$
\begin{aligned}
L \dot{i}(t) & =-v(t)+E, \\
C \dot{v}(t) & =i(t)-\frac{v(t)}{R} .
\end{aligned}
$$

Observe that this switched system can be expressed in the bilinear form as

$$
\begin{gathered}
\dot{i}(t)=-(1-u(t)) \frac{v(t)}{L}+\frac{E}{L}, \\
\dot{v}(t)=(1-u(t)) \frac{i(t)}{C}-\frac{v(t)}{C R},
\end{gathered}
$$

where the control input $u(t) \in\{0,1\}$. To implement a continuous control signal in this converter, a $\Sigma \Delta M$ circuit $[17,38]$ is used. 


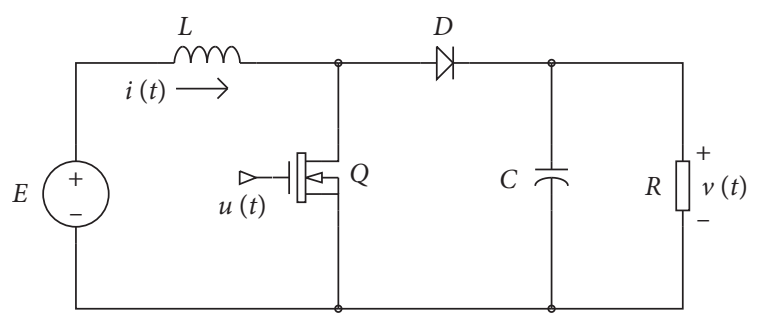

FIGURE 1: Electronic circuit of a boost power converter.

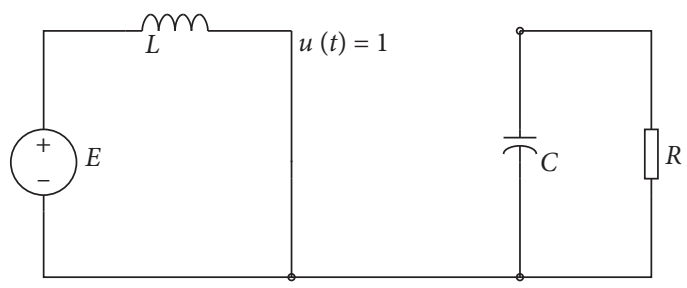

Figure 2: On mode.

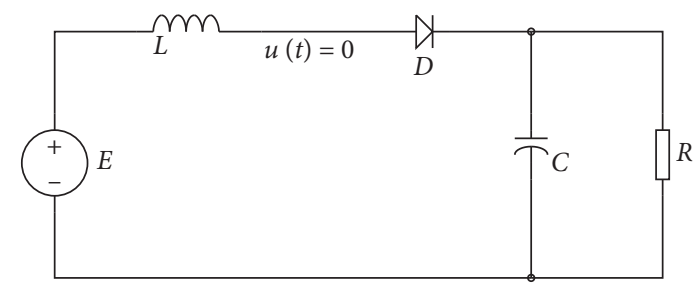

FIgURE 3: Off mode.

2.2. Boost Converter with Perturbations. When nonideal elements and unknown changes in the nominal load $R$ are considered, the boost converter model (3) can be seen as a perturbed system of the form

$$
\begin{gathered}
\dot{i}(t)=-(1-u(t)) \frac{v(t)}{L}+\frac{E}{L}+\phi_{1}(t), \\
\dot{v}(t)=(1-u(t)) \frac{i(t)}{C}-\frac{v(t)}{C R}+\phi_{2}(t),
\end{gathered}
$$

where $\phi_{1}: \mathbb{R} \longrightarrow \mathbb{R}$ and $\phi_{2}: \mathbb{R} \longrightarrow \mathbb{R}$ denote unknown matched uncertainties/perturbations, composed by unknown load changes, differences in the nominal input voltage $E$, uncertainties in the system parameters, and exogenous signals.

2.3. $\Sigma \Delta$ Modulator. To convert a continuous signal to a digital one, a $\Sigma \Delta M[17,39,40]$ may be utilized, allowing the switched synthesis of any feedback controller designed following an average viewpoint. This modulator can be used to translate a continuous average design into a discontinuous one with the property that the equivalent output signal of the modulator matches the input signal generated by the continuous average feedback controller. In this paper, the following $\Sigma \Delta M$ is used (for more details about the modeling of this modulator see [17]).

$$
\begin{array}{r}
\dot{z}(t)=\zeta(t), \\
\dot{x}(t)=u(t)=\frac{1}{2}(1+\operatorname{sign}(\sigma(t))), \\
\sigma(t)=z(t)-x(t) ;
\end{array}
$$

where $\zeta(t)$ is the analogue input signal, and $u(t) \in\{0,1\}$ is the output of the modulator. This modulator is only capable to modulate the input if $\zeta(t) \in[0,1]$. The block diagram of the $\Sigma \Delta M$ is shown in Figure 4 .

2.4. Super-Twisting Algorithm. Consider a relative degree one scalar system:

$$
\dot{s}(t)=u(t)+\psi(t)
$$

where $\psi(t)$ is a Lipschitz uncertainty/perturbation. The STA [28] is a second-order sliding mode control that drives the sliding variable $s$ and its derivatives to zero in finite-time. It generates a continuous control and attenuate the chattering effect by hiding the switching term under an integral. In general, the STA controller is given as

$$
\begin{aligned}
& u(t)=-k_{1}\lfloor s(t)\rceil^{(1 / 2)}+w(t), \\
& \dot{w}(t)=-k_{2}\lfloor s(t)\rceil^{0},
\end{aligned}
$$

where $\left\lfloor\left.\cdot\right|^{p}=|\cdot|^{p} \operatorname{sign}(\cdot)\right.$, and $k_{1}$ and $k_{2}$ are designed to guarantee the finite-time convergence of $s$ and $\dot{s}$ to the origin in finite-time. This controller compensates in finite-time Lipschitz uncertainties/perturbations. However, the generated continuous control signal is unbounded.

To produce a bounded continuous control signal with the characteristics of the STA, in [35], a SSTA is proposed. This controller assures finite-time convergence to the origin of the sliding variable $s$ and its time derivatives while compensating bounded Lipschitz uncertainties/perturbations. The design conditions of such a controller are given in the following theorem.

Theorem 1. [35] Let the scalar system (6) with $\psi(t)$, a bounded Lipschitz perturbation, i.e., $\dot{\psi}(t) \leq \bar{\psi}_{1}$, and $\psi \leq \bar{\psi}_{0} \leq M$. Consider the SSTA controller:

$$
\begin{array}{r}
u(t)=\operatorname{sat}_{U}\left(-k_{1}\lfloor s(t)\rceil^{(1 / 2)}+w(t)\right), \\
\dot{w}(t)=-k_{2}\lfloor s(t)\rceil^{0}, \\
w(0)=0,
\end{array}
$$

where $\lfloor\cdot\rceil^{p}=|\cdot|^{p} \operatorname{sign}(\cdot)$, and

$$
\operatorname{sat}_{U}(y)=\left\{\begin{array}{lll}
y, & \text { if } & |y| \leq M, \\
M\lfloor y\rceil^{0}, & \text { if } & |y|>M,
\end{array}\right.
$$

with SSTA gains, such that

$$
\begin{array}{r}
k_{1}>\sqrt{k_{2}+\bar{\psi}_{1}}, \\
k_{2}>\bar{\psi}_{1} .
\end{array}
$$




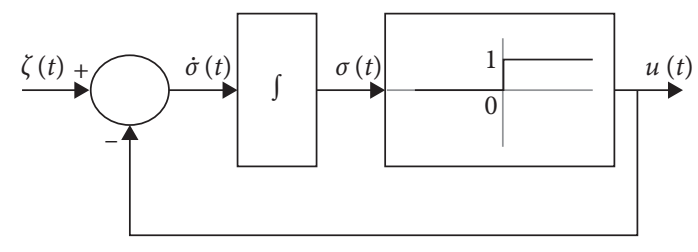

Figure 4: $\Sigma \Delta M$ block diagram.

Then, the control law (8) globally stabilizes the plant (6) in finite-time with a control input $u$ that is continuous with respect to time and satisfies $|u(t)| \leq M$, for all $t \geq 0$.

Note that in comparison with the conventional FOSM, the SSTA generates a bounded continuous control signal and reduces the chattering effect in the system.

2.5. Problem Formulation. Consider the perturbed boost system (4) and define the inductor current error:

$$
e_{i}(t)=i(t)-i^{*}(t)
$$

where $i^{*}: \mathbb{R} \longrightarrow \mathbb{R}$ is the desired inductor current bounded $C^{2}$ function. The current error dynamics takes the form

$$
\dot{e}_{i}(t)=-(1-u(t)) \frac{v(t)}{L}+\frac{E}{L}+\phi_{1}(t)-i^{*}(t) .
$$

It can be seen that the current error dynamics are not directly affected by $\phi_{2}(t)$. Also, along this paper, the following assumptions are necessary.

Assumption 1. The uncertainties/perturbations $\phi_{1}(t)$ are bounded and Lipschitz, i.e.,

$$
\begin{gathered}
\bar{\phi}_{0} \leq \phi_{1}(t) \leq \bar{\phi}_{1}, \\
\left|\dot{\phi}_{1}(t)\right| \leq \bar{\phi}_{2},
\end{gathered}
$$

where $\bar{\phi}_{0}, \bar{\phi}_{1} \in \mathbb{R}$, and $\bar{\phi}_{2} \in \mathbb{R}_{+}$.

Assumption 2. The uncertainties/perturbations $\phi_{2}(t)$ are continuous and bounded, such that

$$
\left|\phi_{3}(t)\right| \leq \bar{\phi}_{3}, \quad \bar{\phi}_{3} \in \mathbb{R}_{+} \text {. }
$$

Under Assumptions 1 and 2, the task is to ensure that the inductor current $i$ tracks the desired inductor current $i^{*}$ exactly by using a SSTA controller after a finite transient, i.e., the problem resides on to stabilize in finite-time the current error (12), $i(t) \longrightarrow i^{*}(t)$ for all $t \geq t_{r}$, where $t_{r}$ is the reaching time, by using a continuous control law $u(t)$.

Note that as it is mentioned in $[17,29]$, to track a desired voltage, two control loops are needed. An inner current control loop and an outer voltage control loop. The objective of this paper is the design of a controller that guarantees the finite-time tracking of a desired current in the presence of bounded Lipschitz uncertainties/perturbations.

\section{Control Design}

Consider the perturbed boost converter (4) and define $e_{i}(t)$ as the sliding variable. To guarantee $i(t) \longrightarrow i^{*}(t)$ in finite-time, it is necessary to select a suitable controller capable to achieve such a task. Observe that $e_{i}$ has relative degree one, and it is assumed that $\phi_{1}$ is a bounded Lipschitz perturbation. Hence, it is possible to use an SSTA controller $[34,35]$. The next theorem gives sufficient condition to the design of the SSTA controller for the internal current control loop of the boost converter.

Theorem 2. Consider the error dynamics of the inductor current in the boost converter (12), with a bounded Lipschitz perturbation $\phi_{1}(t)$, such that

$$
\bar{\phi}_{0}<-\frac{E}{L}+i^{*}(t) \leq \phi_{1}(t) \leq \frac{v(t)}{L}-\frac{E}{L}+i^{*}(t)<\bar{\phi}_{1},
$$

and $\left|\dot{\phi}_{1}(t)\right| \leq \bar{\phi}_{2}$. By using the controller,

$$
\begin{array}{r}
u(t)=\frac{1}{2}+\operatorname{sat}_{U}\left(\frac{L}{v(t)}\left(u_{\text {neq }}(t)+\bar{u}(t)\right)\right), \\
u_{\text {neq }}(t)=\frac{v(t)}{2 L}-\frac{E}{L}+\dot{i}^{*}(t), \\
\bar{u}(t)=-k_{1}\left\lfloor e_{i}(t)\right\rceil^{(1 / 2)}+w(t), \\
\dot{w}(t)=-k_{2}\left\lfloor e_{i}(t)\right\rceil^{0},
\end{array}
$$

where $\left\lfloor\left.\cdot\right|^{p}=|\cdot|^{p} \operatorname{sign}(\cdot)\right.$, and

$$
\operatorname{sat}_{U}(y)=\left\{\begin{array}{lll}
y, & \text { if } & |y| \leq \frac{1}{2} \\
\frac{1}{2}\left\lfloor\left. y\right|^{0},\right. & \text { if } & |y|>\frac{1}{2}
\end{array}\right.
$$

with the SSTA gain designed, such that

$$
\begin{array}{r}
k_{1}>\sqrt{k_{2}+\bar{\phi}_{2}}, \\
k_{2}>\bar{\phi}_{2} .
\end{array}
$$

Then, the tracking error converges to the origin after $a$ finite transient, i.e., $e_{i}(t)=\dot{e}_{i}(t)=\ddot{e}_{i}(t)=0$ for all $t>t_{r}$, where $t_{r}$ is the reaching time, and the control effort remains in the inherent bounds, i.e., $u(t) \in[0,1]$ for all $t \geq 0$.

Proof. To analyze the dynamics of the tracking error in the sliding mode, let

$$
u(t)=\frac{1}{2}+\frac{L}{v(t)}\left(u_{\text {neq }}(t)+\bar{u}(t)\right) .
$$

By substituting this controller in the tracking error dynamics (12), it can be seen that

$$
\dot{e}_{i}(t)=\bar{u}(t)+\phi_{1}(t) .
$$

Assume that for $t>t_{r}$, the sliding mode is achieved, i.e., $e_{i}(t)=\dot{e}_{i}(t)=\ddot{e}_{i}(t)=0$; then,

$$
\bar{u}(t)=-\phi_{1}(t) .
$$

Hence, if the sliding mode is achieved, the proposed controller is capable to compensate exactly the matched uncertainties/perturbations $\phi_{1}$. Note that if $\phi_{1}$ satisfies the 
inequality (15), the control signal satisfies the inequality $0 \leq u(t) \leq 1$ for all $t>t_{r}$.

Now, observe that the tracking error dynamics (20) resemble the system of Theorem 1, and the conditions of such theorem are satisfied. Hence, the finite-time convergence of the tracking error dynamics is guaranteed.

Note that the proposed controller has a symmetric structure, but it contains an offset that keeps the control signal in the interval $[0,1]$.

Remark 1. Once the sliding variable $e_{i}(t)$ has converged to the origin, the controller $\bar{u}(t)=-\phi_{1}(t)$ for $t>t_{r}$. Hence, the control signal $\bar{u}(t)$ reconstructs the negative of the perturbation and compensates the perturbation in finite-time. In comparison with a FOSM, the continuity of the SSTA allows to know exactly the value of the perturbation without filtering [28].

Observe also that $u_{\text {neq }}$ in (9) is the nominal equivalent control signal that eliminates the known dynamic of the sliding variable. However, it is possible to consider $u_{\text {neq }}(t)=$ 0 and let the SSTA to reconstruct all the tracking error dynamics. The next lemma states this result.

Lemma 1. Under the conditions of Theorem 1 and Assumption 2, by using the controller,

$$
\begin{array}{r}
u(t)=\frac{1}{2}+\operatorname{sat}_{U}\left(\frac{L}{v(t)} \bar{u}(t)\right), \\
\bar{u}(t)=-k_{1}\left\lfloor e_{i}(t)\right\rceil^{(1 / 2)}+w(t), \\
\dot{w}(t)=-k_{2}\left\lfloor e_{i}(t)\right\rceil^{0},
\end{array}
$$

where $\left\lfloor\left.\cdot\right|^{p}=|\cdot|^{p} \operatorname{sign}(\cdot)\right.$, and

$$
\operatorname{sat}_{U}(y)=\left\{\begin{array}{lll}
y, & \text { if } & |y| \leq \frac{1}{2}, \\
\frac{1}{2}\lfloor y\rceil^{0}, & \text { if } & |y|>\frac{1}{2} .
\end{array}\right.
$$

If SSTA gains are designed such that

$$
\begin{array}{r}
k_{1}>\sqrt{k_{2}+\bar{\psi}(t)}, \\
k_{2}>\bar{\psi}(t),
\end{array}
$$

with

$$
\bar{\psi}(t) \geq\left|\frac{v(t)}{2 \mathrm{LCR}}-\ddot{i}^{*}(t)\right|+\frac{\bar{\phi}_{3}}{2 L}+\bar{\phi}_{2} .
$$

Then, the tracking error converges to the origin after a finite transient, i.e., $e_{i}(t)=\dot{e}_{i}(t)=\ddot{e}_{i}(t)=0$ for all $t>t_{r}$, where $t_{r}$ is the reaching time, and the control effort remains in the inherent bounds, i.e., $u(t) \in[0,1]$ for all $t \geq 0$.

Proof. The proof is obtained following a similar procedure as in Theorem 2 and a straightforward computation of the bound $\bar{\psi}(t)$.
If the controller is designed satisfying the above results, the bound of the control signal is guaranteed, and it can be fed to $\Sigma \Delta M$ to generate a suitable control signal for the boost converter assuring the tracking in finite-time of the desired current in the presence of the uncertainties/perturbations.

\section{Simulation Results}

To validate the above results, some MATLAB simulations are presented. Consider a boost converter with $L=10 \mathrm{mH}$, $C=2.2 \mu \mathrm{F}$, and $E=12 \mathrm{~V}$. The desired current is

$$
i^{*}(t)=0.8 \sin (t)+1 .
$$

The considered unknown perturbation is

$$
\phi_{1}(t)=3 \sin (16 \cos (\pi t))+500,
$$

and $\phi_{2}(t)$ is constructed by changes in the nominal load $R=500 \Omega$, such that the real load $\bar{R}$ has the form

$$
\bar{R}(t)=\left\{\begin{array}{lll}
560 \Omega, & \text { if } \quad 0 \leq t \leq 10 \vee t \geq 30, \\
200 \sin (10 \pi t)+300, & \text { if } \quad 10<t \leq 20 \\
150 \Omega, & \text { if } \quad 20<t \leq 30
\end{array}\right.
$$

Note that the proposed load is a continuous function that is bounded. In the simulation, it is considered $\bar{\phi}_{2}=15000$ as the bound of the perturbation $\phi_{1}$, and the controller is designed as given in Theorem 2 .

The results obtained by applying the designed SSTA to the boost converter in a time window $T=40 \mathrm{~s}$ with a sample step of $\Delta t=1 \times 10^{-6} \mathrm{~s}$ are shown in Figure 5. It can be seen that the current converges to the desired trajectory in finitetime despite the presence of the perturbation.

It is worth to mention the effect of the perturbation in the voltage of the load, and this state is not controlled, so this behavior is expected. To guarantee that the voltage is not affected by the perturbation, an external control loop that modified the desired current needs to be designed. However, observe that the tracking error (Figure 6) converge to the origin in finite-time, showing that $i(t) \longrightarrow i^{*}(t)$ in the same manner. The designed control signal is retrieved in Figure 7. Observe that the control signal is continuous and remains in the interval $[0,1]$ in the time interval.

4.1. Chattering Analysis. According to Levant [32], in the sliding mode control, the chattering is caused by the high, theoretically infinite, frequency of control switching and reveals itself as high-frequency dangerous vibrations of the whole system. In power systems, this phenomenon is known as ripple.

Definition 1. [32] Consider an absolutely continuous scalar signal $\xi(t) \in \mathbb{R}$ and $t \in[0, T]$. Also, let $\bar{\xi}(t) \in \mathbb{R}$ be an absolutely continuous nominal signal, such that $\xi(t)$ is considered as its disturbance. Let $\Delta \xi(t)=\xi(t)-\bar{\xi}(t)$. Define the $L_{2}$ chattering of the signal as 

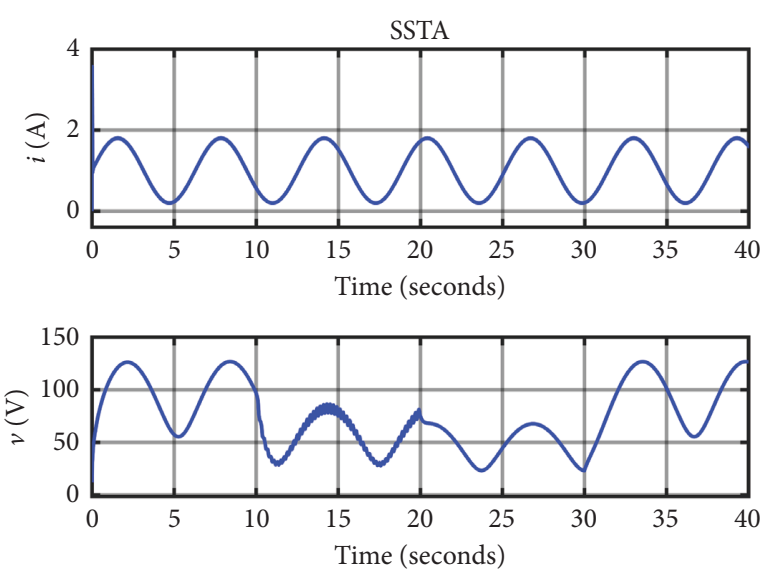

FIGURE 5: Boost current and voltage with the SSTA controller.
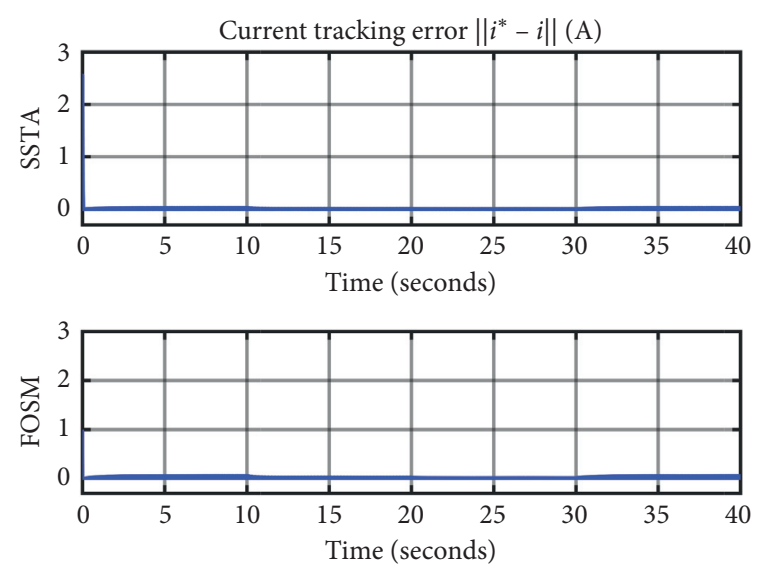

Figure 6: Tracking error for both controllers.

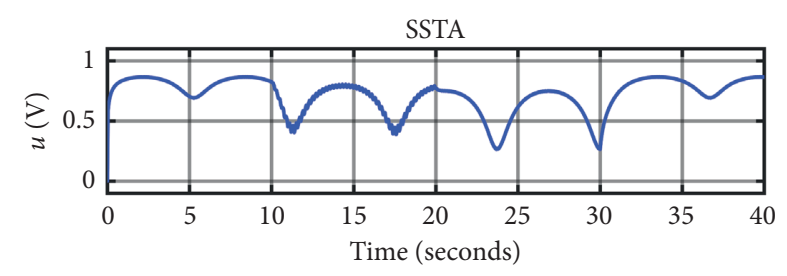

FIgURE 7: SSTA control signal.

$$
\operatorname{chat}_{L_{2}}=\left(\int_{0}^{T} \Delta \dot{\xi}^{2}(t) \mathrm{d} t\right)^{(1 / 2)} .
$$

In power systems, to evaluate the performance of the power converter, the ripple is normally measured by computing the energy contained in the error signal [29].

For comparison purposes, a FOSM controller [20,29] is applied to the boost converter considering the load change in the same manner as in the SSTA case. The considered controller is

$$
u(t)=\frac{1}{2}\left(1-\operatorname{sign}\left(e_{i}(t)\right)\right) .
$$

The inductor current behavior is shown in Figure 8 and its respective error in Figure 6. Observe that the tracking task
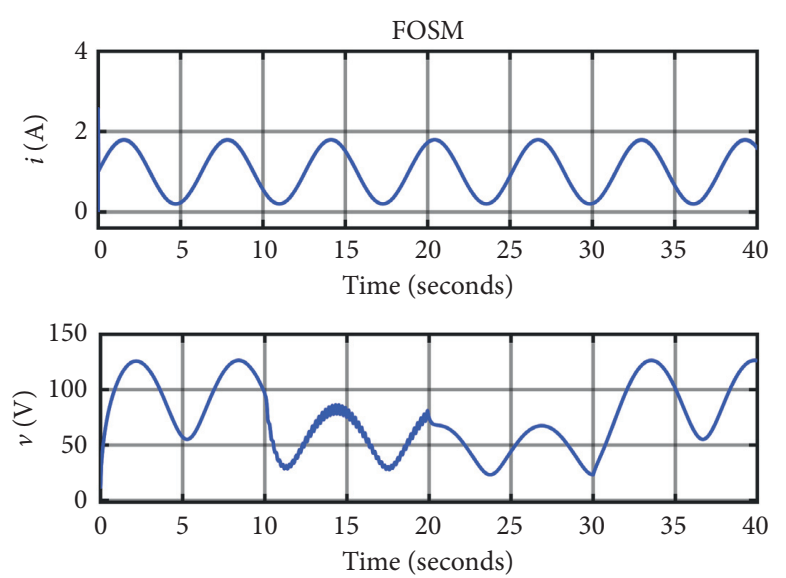

Figure 8: Boost current and voltage with the FOSM controller.

is also achieved, i.e., $i(t) \longrightarrow i^{*}(t)$ in finite-time despite the perturbation. The controller is not continuous, but it can be applied to the boost converter without needing $\Sigma \Delta M$.

In the performed simulations, it can be seen that the difference in the performance of the two controllers is basically in the size of the chattering, depicted in Figure 6. However, by only seeing the picture, it is very hard to decide if any of the two controllers gives any advantage.

To visualize in a better way the differences between the two control strategies, an energy and chattering analysis has been performed. First, the energy of the tracking error signal [41] is obtained as

$$
\text { Energy }=\int_{t_{r}}^{T} e_{i}^{2}(t) \mathrm{d} t
$$

Afterwards, a chattering analysis $[32,42]$ is performed by computing the level of chattering in the $L_{2}$ space of the tracking error signal:

$$
\operatorname{chat}_{L_{2}}=\left(\int_{t_{r}}^{T} \dot{e}_{i}^{2}(t) \mathrm{d} t\right)^{(1 / 2)} .
$$

The analyses are performed for different sample times assuming that the error signal has passed the reaching phase, i.e., the analysis is performed for $t \in\left[t_{r}, T\right]$, with $t_{r}=0.2 \mathrm{~s}$. The result is summarized in Tables 1 and 2 .

By analyzing the energy signal of both controllers, it is evident that the use of a SSTA diminishes the energy of the error signal. However, the chattering measurement remains more or less the same. It was proved in $[32,33]$ that the chattering of a continuous sliding mode controller is infinitesimal while one of a FOSM controller is bounded. It seems that the use of $\Sigma \Delta M$ changes the chattering type of the SSTA to a bounded one. Hence, the only advantage that can be seen by the performed analysis is the decrement in the energy of the error signal by the use of the SSTA.

4.2. Power Efficiency. In several applications as hybrid electric vehicles or fuel cell vehicles, energy storage is employed to reduce the cost and to improve the performance of the system [1]. In these applications, the voltage 
TABLE 1: Energy and chattering analysis for the SSTA controller.

\begin{tabular}{lcc}
\hline Sample step & Energy & Chattering \\
$1 \times 10^{-3}$ & 3678 & 43611.1 \\
$1 \times 10^{-4}$ & 3.01 & 21857.51 \\
$1 \times 10^{-5}$ & 0.02 & 19892.86 \\
$1 \times 10^{-6}$ & $2.16 \times 10^{-4}$ & 19710.9 \\
$1 \times 10^{-7}$ & $2.15 \times 10^{-6}$ & 19692.87 \\
\hline
\end{tabular}

TABLE 2: Energy and chattering analysis for the FOSM controller.

\begin{tabular}{lcc}
\hline Sample step & Energy & Chattering \\
$1 \times 10^{-3}$ & 974.8 & 24175.92 \\
$1 \times 10^{-4}$ & 5.17 & 21275.37 \\
$1 \times 10^{-5}$ & 0.05 & 19743.29 \\
$1 \times 10^{-6}$ & $4.72 \times 10^{-4}$ & 19687.46 \\
$1 \times 10^{-7}$ & $4.711 \times 10^{-6}$ & 19681.85 \\
\hline
\end{tabular}

level is normally lower than the required, and power converters are widely used. These systems require good efficiency in the energy consumption, since they are working constantly over transient states. This makes it necessary to analyze how the efficiency of the boost converter is affected by the controller. The power efficiency is defined by the ratio of the output power $P_{o}$ to the input power $P_{i}$.

$$
\eta=\frac{P_{o}}{P_{i}}=\frac{\left(v_{\mathrm{RMS}}^{2} / R\right)}{E i_{\mathrm{RMS}}}
$$

where $v_{\mathrm{RMS}}$ and $i_{\mathrm{RMS}}$ denote the root mean square value of the load voltage and the inductor current, respectively, over the time interval $\left[0, t_{f}\right]$. Assume that the boost converter is performing a current regulation task over the range $0.03 \mathrm{~A}-3 \mathrm{~A}$ and that there are not any uncertainties/perturbations that affect the behavior of the system, i.e., $\phi_{1}(t)=\phi_{2}(t)=0$. Three controllers are considered for comparison purposes: (1) a saturated linear quadratic (LQ) controller designed for the linearized system around the equilibrium point defined by the desired current $i^{*}$, (2) a FOSM controller defined in the previous section, and (3) the proposed SSTA. In Figure 9, the power efficiency of the boost converter with the considered controllers, obtained by simulation with a sample step $\Delta t=1 \times 10^{-6}$, is depicted. Note that the use of a sliding mode control technique improves considerably the efficiency in comparison with the LQ controller. Observe also that the performed analysis is very simple, and more complex analysis can be performed for the proposed controller as the one given in [43].

4.3. Discussion. The presented result is focused on the design of the inner current control loop of the boost converter. As mentioned previously, the objective of the power converters is to deliver a desired voltage that can be constant or time varying depending on the application. There are several control methodologies that can be used to design the outer loop. In [17], a frequency-based approach is used, in [29], the desired current is designed by using a SMC approach, while in [26], an MPC approach is used. The chosen approach will depend on the conditions of the converter and the control objective.
In this paper, the considered load does not have a specific form, and it is seen as a perturbation. The form of the load depends on the specific application, and the only restriction is that it must be bounded and Lipschitz. In the microgrid applications $[25,26]$, the load can be modeled as the connection of several CPLs. This type of load has the characteristic that its model is a first-order vectorial dynamic equation and can be considered as a Lipschitz-bounded perturbation.

To show the applicability of the proposed approach, a voltage regulation scenario is presented with a CPL. For simulation purposes, the parameters of the considered CPL were taken from [26]. The desired voltage $v^{*}$ is assumed as constant, and the error $e_{v}(t)=v(t)-v^{*}$ is taken as the sliding variable. The desired current that guarantees the voltage regulation is constructed by an asymptotic sliding mode (ASM) controller [28]. This controller provides asymptotic regulation of the desired voltage by using a differentiable desired current $i^{*}$. Once more, three controllers are compared: (1) the saturated LQ, (2) the FOSM, and (3) the SSTA. The simulation was performed with a sample step $\Delta t=1 \times 10^{-6} \mathrm{~s}, v^{*}=100 \mathrm{~V}$, and a nominal load resistor $R=500 \Omega$. The used perturbation $\phi_{1}(t)$ is defined in (24), and $\phi_{2}(t)$ is composed by a parallel arrangement of a resistor load of $60 \Omega$ and the CPL. The obtained results are shown in Figure 10. The LQ controller is uncapable to deal with the perturbations as it is shown in Figure 10(c). In general, the used controller in the outer loop shapes the convergence to the desired voltage. In the considered case, the ASM guarantees asymptotic convergence of $e_{v}(t)$ to the origin once $i(t)=i^{*}(t)$ (Figures 10(a) and 10(b)). The proposed inner current control loop guarantees the tracking in finitetime. Note that the desired current $i^{*}(t)$ generated by the ASM controller is time varying for both the FOSM and the SSTA, and it guarantees the compensation of the perturbations. The error tracking for the voltage and the current are shown in Figures 11 and 12, respectively.

\section{Implementation}

The boost converter prototype is designed to work with a $12 \mathrm{~V}$ input source and a maximum of $3 \mathrm{~A}$. The PCB layout of the converter is shown in Figure 13. Table 3 indicates the technical specifications of the converter, obtained with a duty cycle of $70 \%$ that gives the highest efficiency of the converter (Figure 14).

The inductor current $i$ is measured by an ACS723 sensor and the capacitor voltage $v$ by a potential divider. The data acquisition is made through a STM32 Discovery development card. The SSTA is embedded in the STM32 Discovery development card. The control signal generated by the controller is feed to $\Sigma \Delta M$. In Figure 15, the constructed prototype is shown. The voltage is given by a commuted source, and an oscilloscope was used to verify the signals in the prototype. To eliminate external magnetic perturbations, the current sensor is in a Faraday cage. The measurements are processed by the STM32 Discovery development card that is connected to a personal computer that displays the 


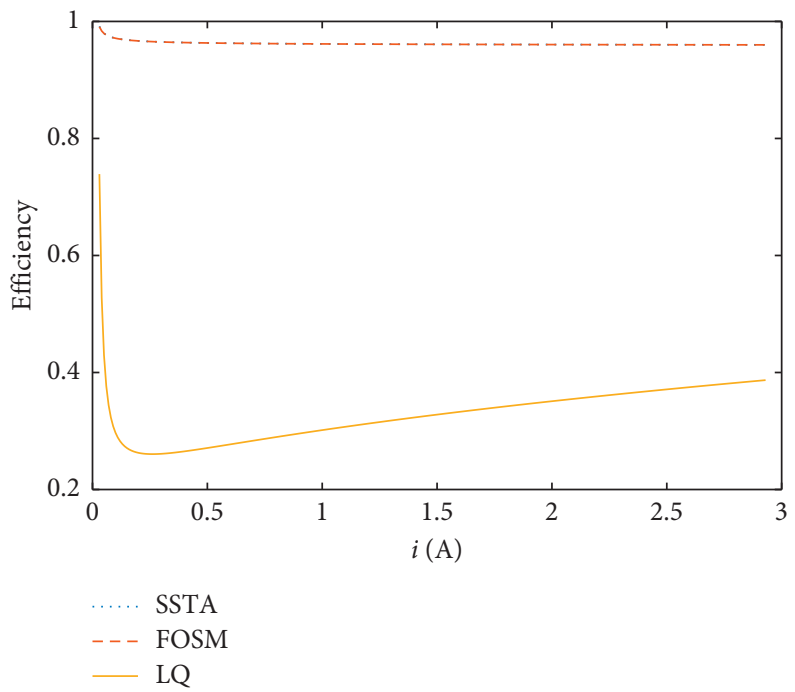

FIGURE 9: Efficiency of the boost converter for different desired current values.
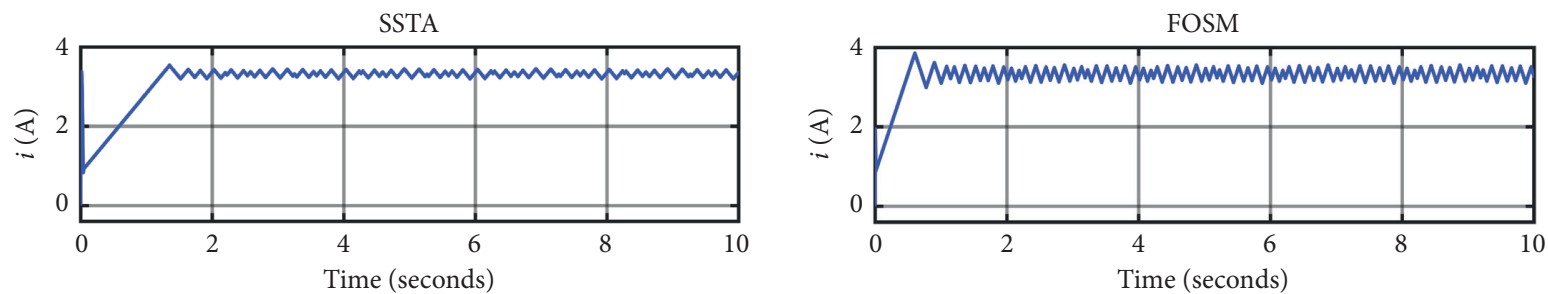

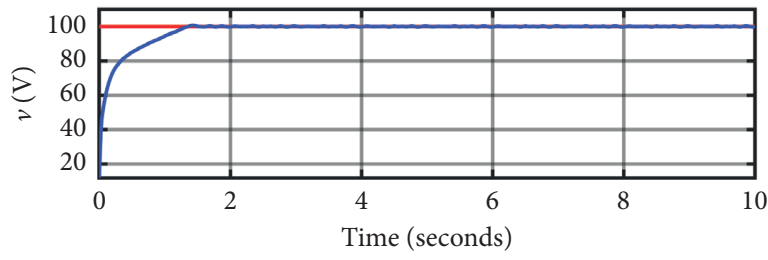

(a)

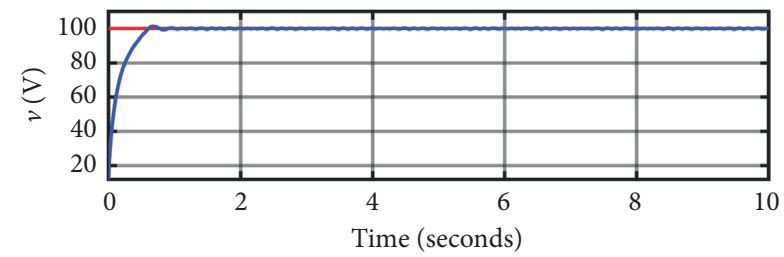

(b)
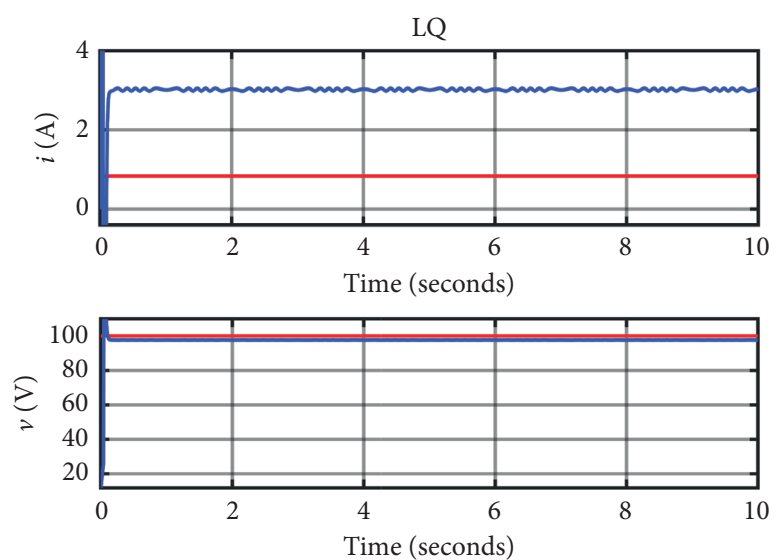

(c)

FIGURE 10: Voltage tracking (reference, red line and boost converter behavior, blue line). (a) SSTA controller. (b) FOSM controller. (c) LQ controller. 

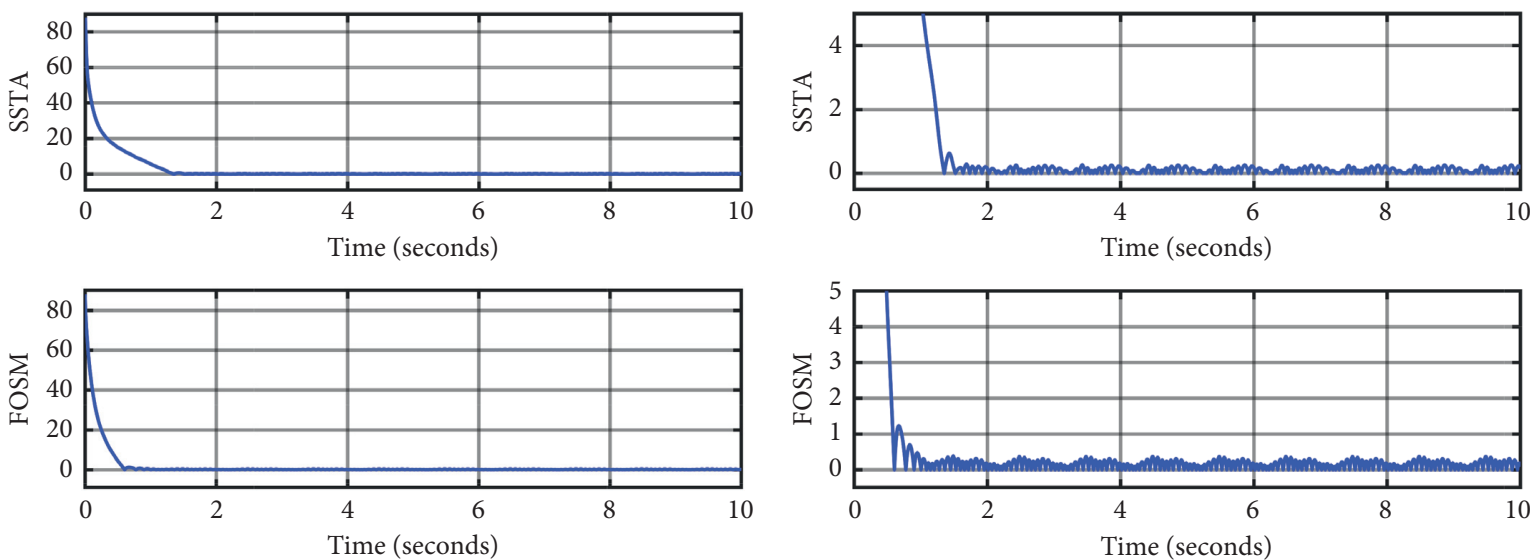

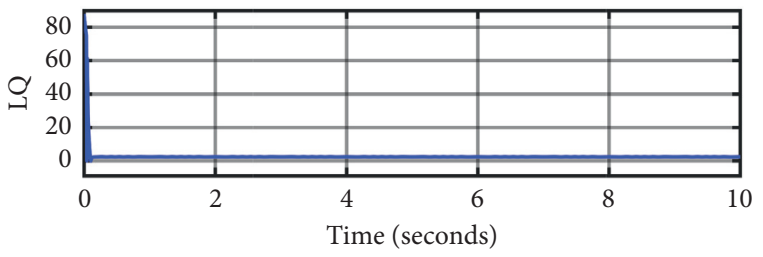

(a)

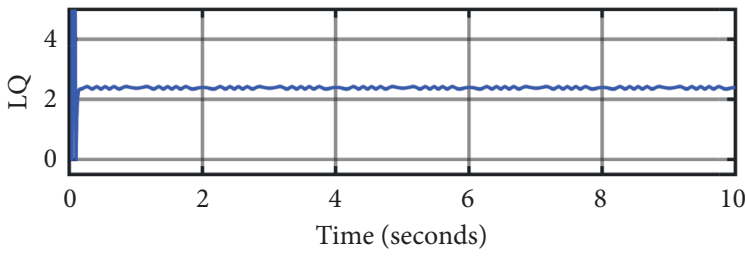

(b)

Figure 11: Voltage error tracking. (a) Voltage tracking error $\left\|v^{*}-v\right\|[V]$. (b) Zoom.
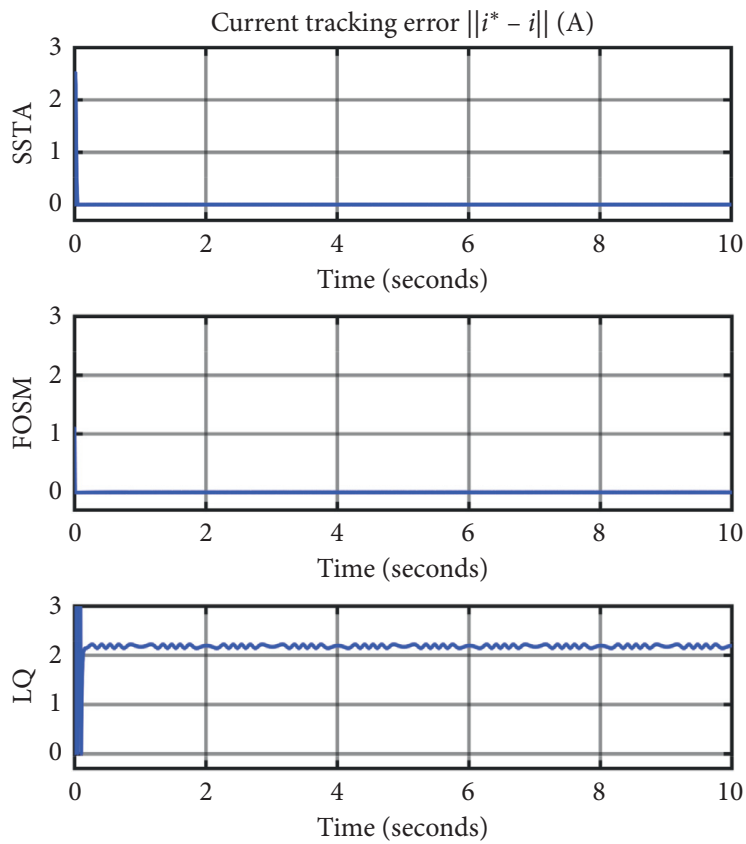

FIgURE 12: Current error tracking.

necessary graphs for the experiments. The scheme of the proposed approach is illustrated in Figure 16.

Two experiments are developed in the prototype using the proposed SSTA approach. First, a regulation test is performed, assuming $i^{*}=0.5 \mathrm{~A}$. An unknown change in the load is considered. In the experiment, a $47 \Omega$ resistor is connected in parallel to the nominal one around $t=7 \mathrm{~s}$ (Figure 17). The results obtained with the oscilloscope are shown in Figures 18 and 19. Observe that the current converges to the desired value in finite-time, and as in the simulation, the voltage is affected by the perturbation. Note that the SSTA reconverge after the load change. This is an expected behavior in the experiment, since the Lipschitz condition is not fulfilled, and the controller loses its convergence. However, after perturbation is applied, the tracking error reconverges to the origin 


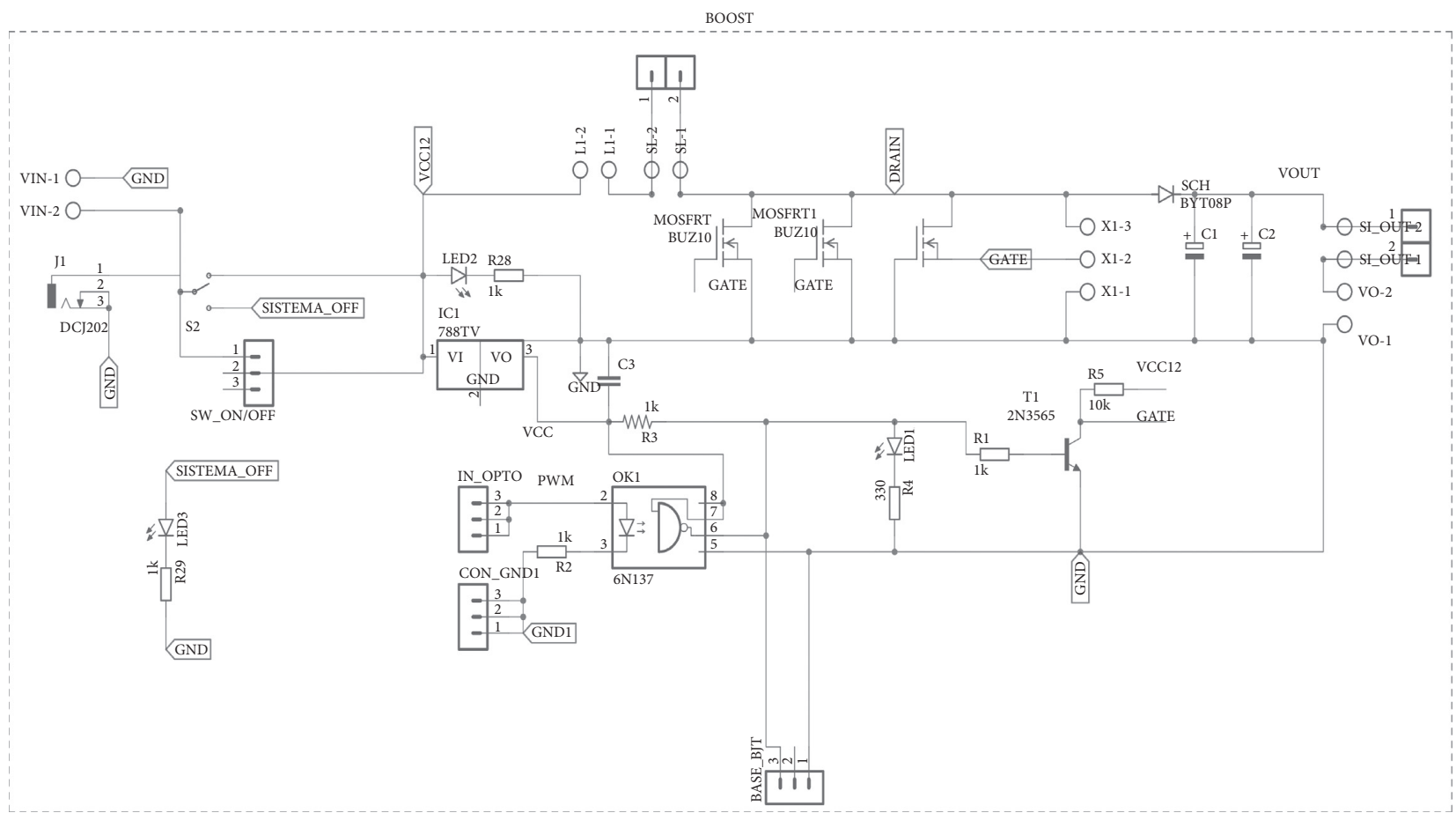

FIgURe 13: Boost converter PCB.

TABLE 3: Boost converter specifications.

\begin{tabular}{lcc}
\hline Specification & Value & Units \\
\hline Load resistance, $R$ & 560 & $\Omega$ \\
Inductor, $L$ & 10 & $\mathrm{mH}$ \\
Capacitor, $C$ & 2200 & $\mu \mathrm{F}$ \\
Output power, $P_{o}$ & $\mathrm{~W}$ \\
Input power, $P_{i}$ & $\mathrm{~W}$ \\
Frequency & 3.09 & $\mathrm{~W}$ \\
Input supply voltage, $E$ & 5 & $\mathrm{kHz}$ \\
Ripple & 12 & $\mathrm{~V}$ \\
Output voltage, $v_{o}$ & 0.02 & $\%$ \\
Duty cycle, $D$ & 31.65 & $\mathrm{~V}$ \\
Efficiency, $\eta$ & 70 & $\%$ \\
Load resistor current, $i_{o}$ & 58.16 & $\%$ \\
Inductor current, $i$ & 56.51 & $\mathrm{~mA}$ \\
\hline
\end{tabular}

(Figure 17(b)). The applied control signal is continuous and remains in the set $[0,3.3] \mathrm{V}$ that is equivalent to the logic set $[0,1]$.

Now, for comparison purposes, a FOSM controller is also implemented. The controller is constructed in a PCB following the scheme proposed in [17]. The scheme of the FOSM strategy is shown in Figure 20. This strategy was implemented completely in hardware, and the development card was used only for data acquisition. The results obtained for this controller are shown in Figures 21-23. Observe that this controller is capable to guarantee in finite-time the control objective, and it is not affected by the use of nonLipschitz perturbations. But it generates more chattering than the SSTA.

Finally, a tracking experiment was performed. The desired current has a sinusoidal profile, a SSTA controller is implemented, and the same source of perturbation is applied. The results obtained with the oscilloscope are shown in Figures 24 and 25. Observe that the current follows the desired sinusoidal signal in finite-time, and the control signal is bounded. But, as in the regulation experiment, the SSTA loses convergence around $t=7 \mathrm{~s}$ due to non-Lipschitz perturbations (Figure 26).

Figure 27 shows the efficiency of the implemented controllers. The experiments were carried out with an initial condition of $0.3 \mathrm{~A}$, and the desired current was modified in a range from 0.3 to $0.9 \mathrm{~A}$. The efficiency is computed considering the transient and steady state behavior of the boost converter. However, it is well known that the efficiency is affected by the frequency characteristic of the control input and the elements used in the implementation of the controller. 


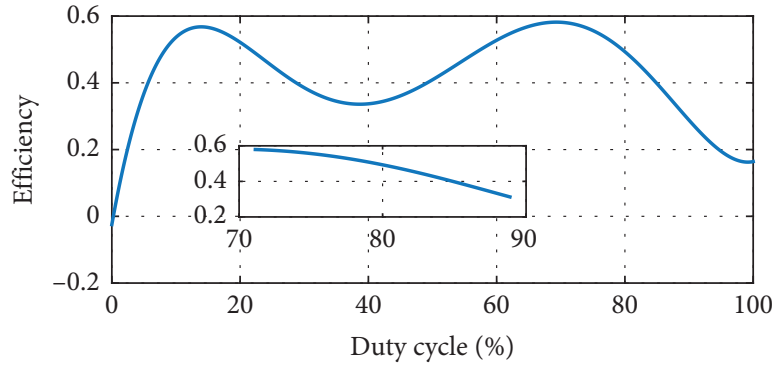

(a)

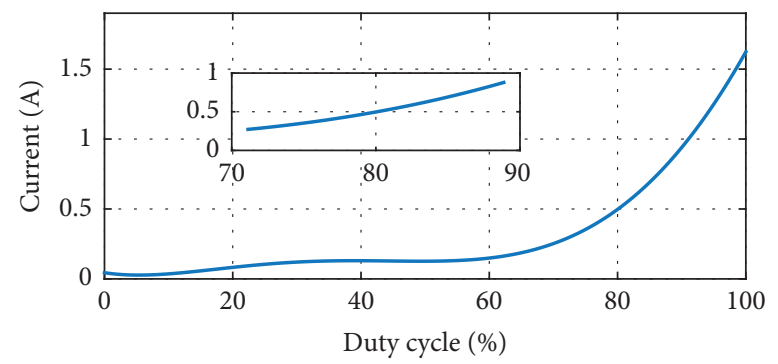

(c)

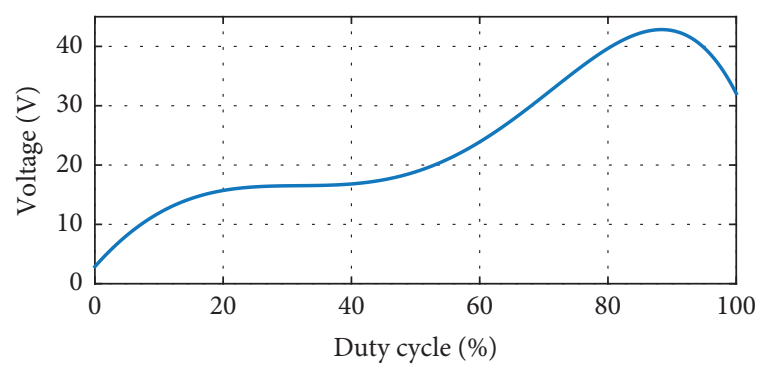

(b)

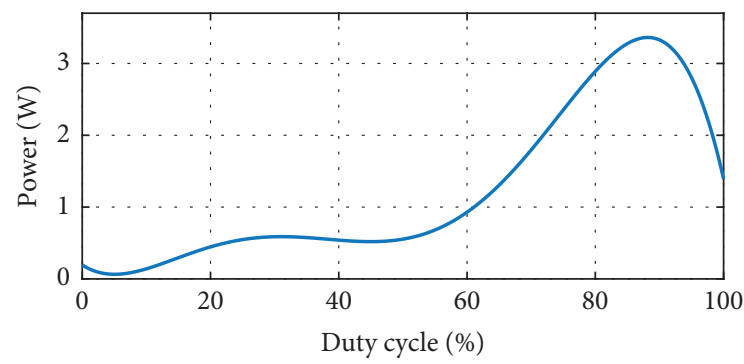

(d)

Figure 14: $\eta-D, v_{o}-D, i-D$, and $P_{o}-D$ characteristic curves of the boost converter. (a) Efficiency vs duty cycle. (b) Output voltage vs duty cycle. (c) Inductor current vs duty cycle. (d) Output power vs duty cycle.

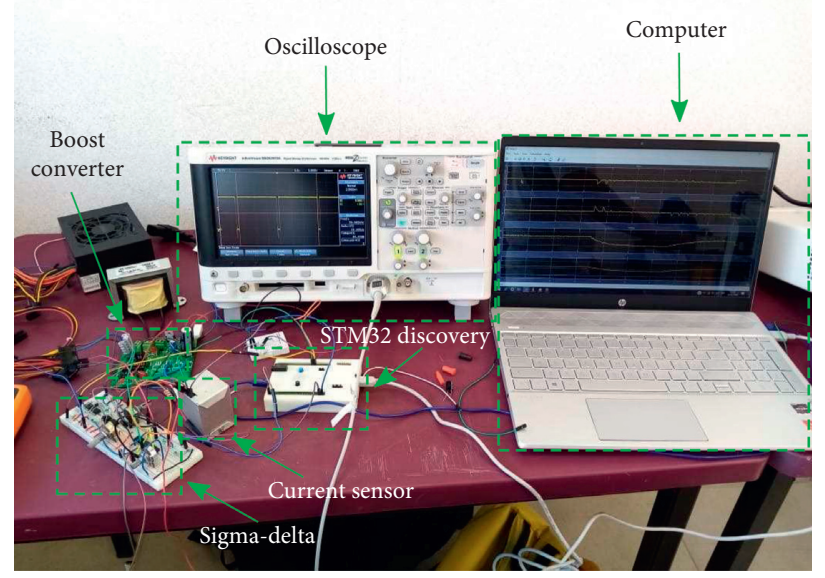

Figure 15: Photograph of the prototype.

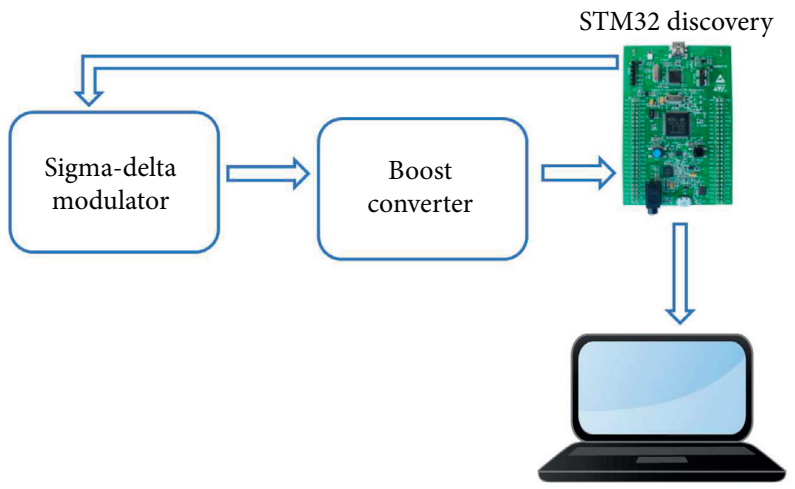

FIGURE 16: Boost converter prototype scheme for the SSTA controller. 


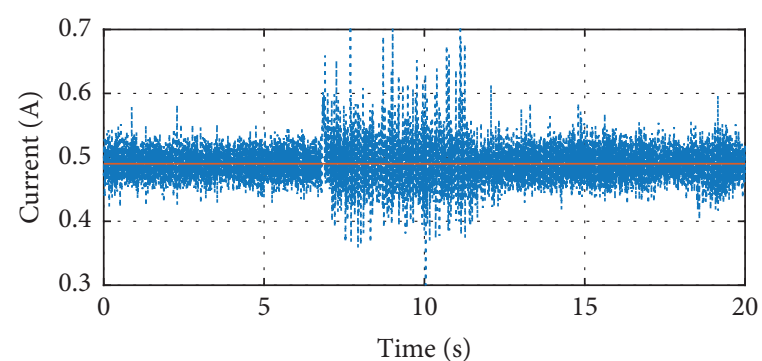

$\cdots+i(t)$

$-i^{*}(t)$

(a)

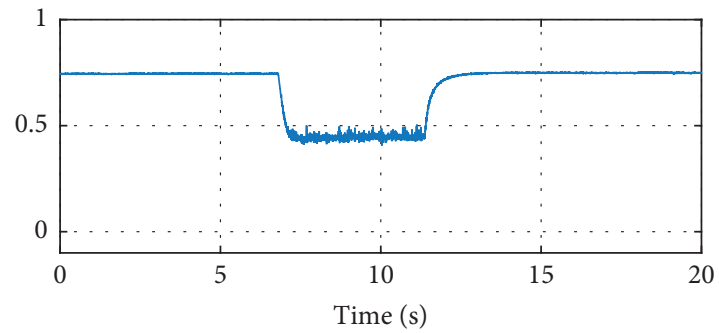

(c)

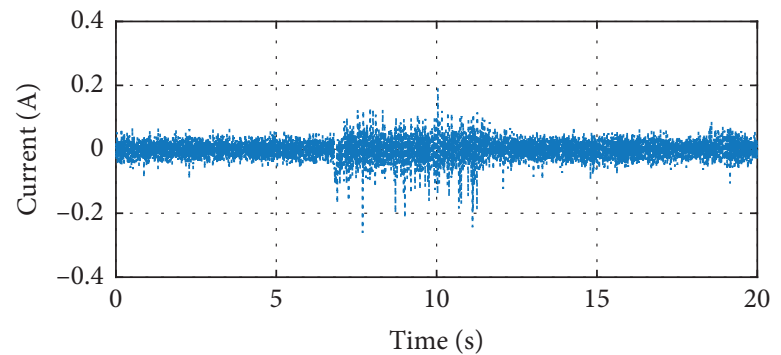

(b)

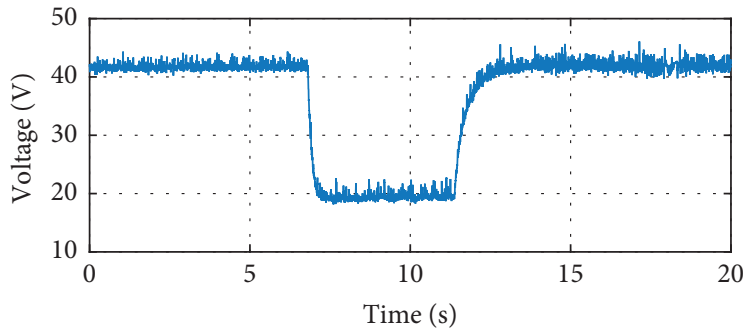

(d)

Figure 17: Boost converter response to disturbances, SSTA controller. (a) Desired current and measured current. (b) Error. (c) Control action. (d) Output voltage.

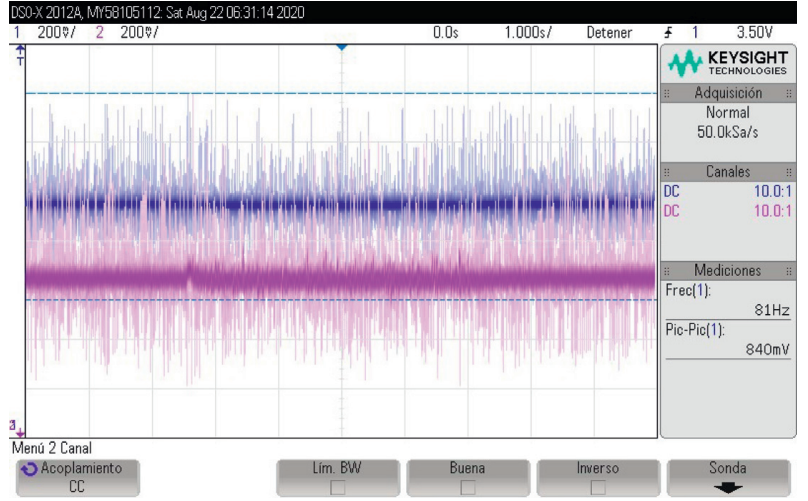

FIGURE 18: Desired current (blue) and measured current (magenta) for the SSTA controller.

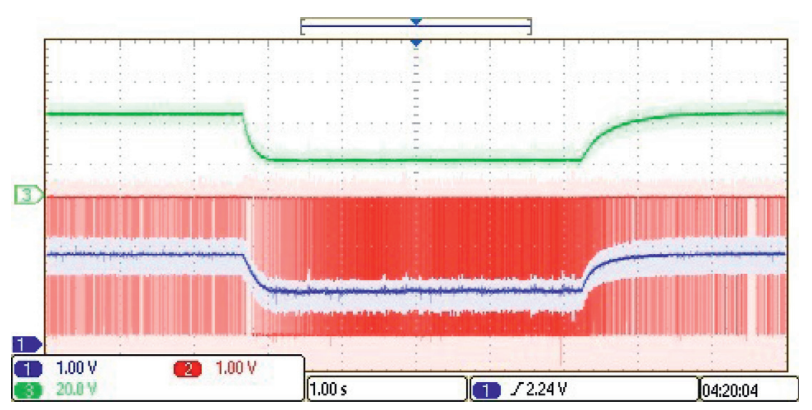

FIGURE 19: Output voltage (green), SSTA controller signal (blue), and $\Sigma \Delta M$ output (red).

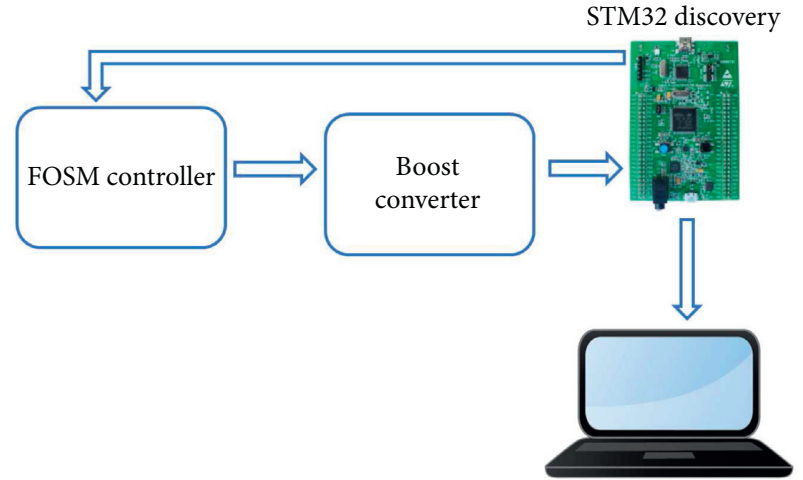

FIGURE 20: Boost converter prototype scheme for the FOSM controller.

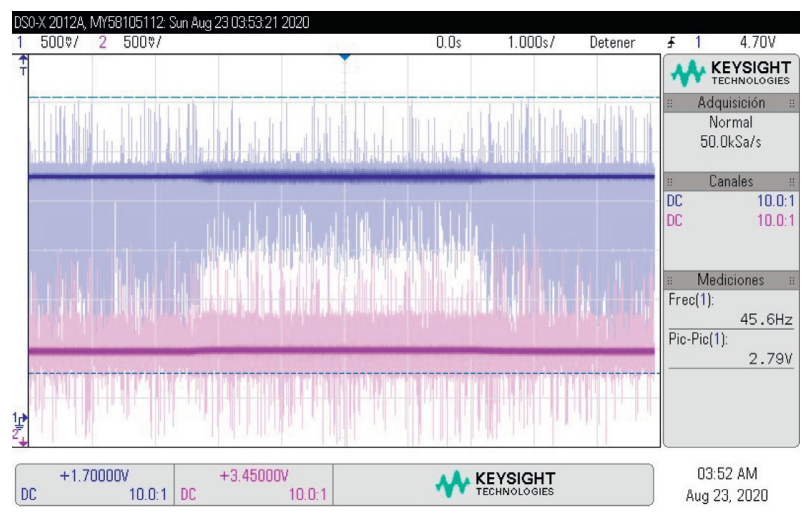

FIGURE 21: Desired current (magenta) and measured current (blue) for the FOSM controller. 


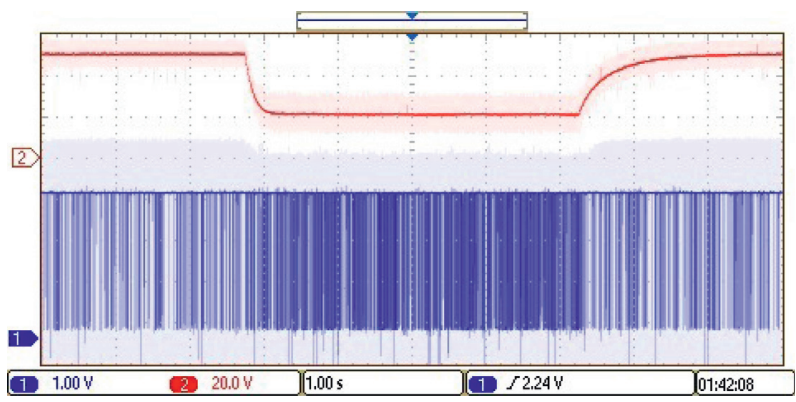

FIgURE 22: Output voltage (red) and FOSM controller signal (blue).

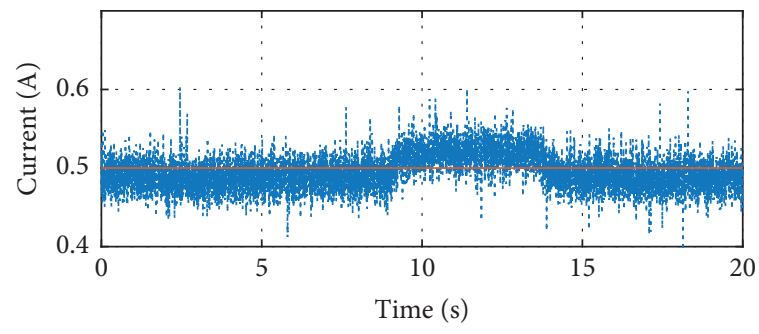

$i(t)$

$-i^{*}(t)$

(a)

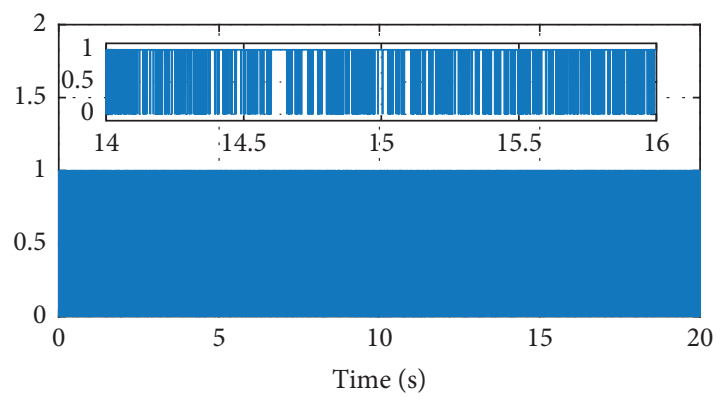

(c)

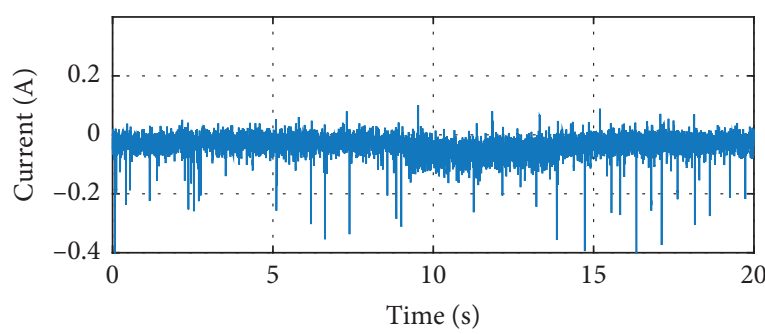

(b)

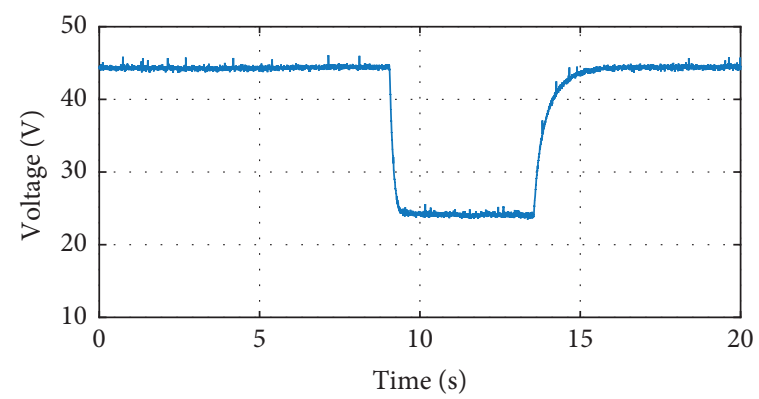

(d)

Figure 23: Boost converter response to disturbances, FOSM controller. (a) Desired current and measured current. (b) Error. (c) Control action. (d) Output voltage.

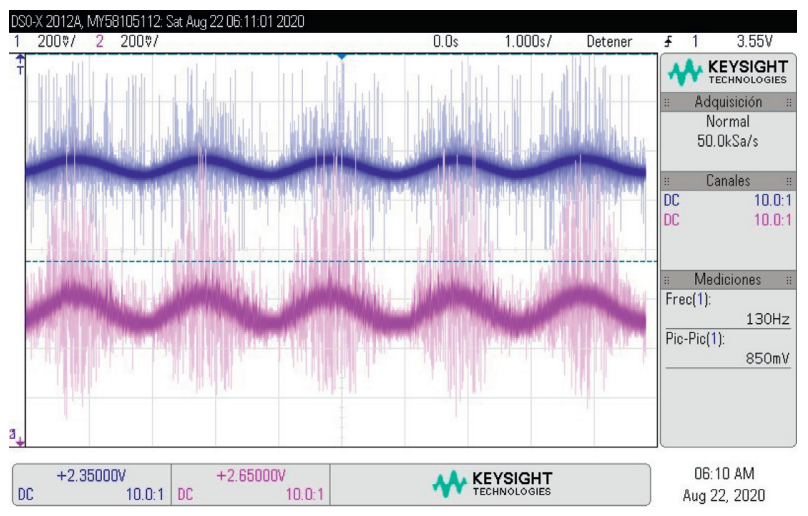

Figure 24: Desired current path (blue) and measured current (magenta).

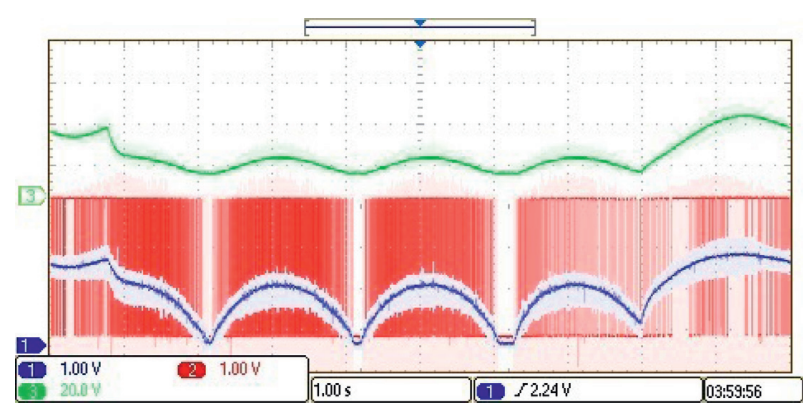

FIGURE 25: Output voltage (green), SSTA controller signal (blue), and $\Sigma \Delta M$ output (red) for trajectory tracking. 


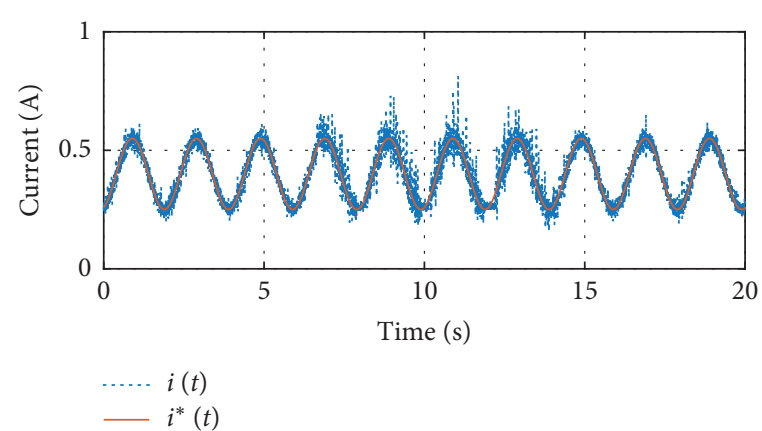

(a)

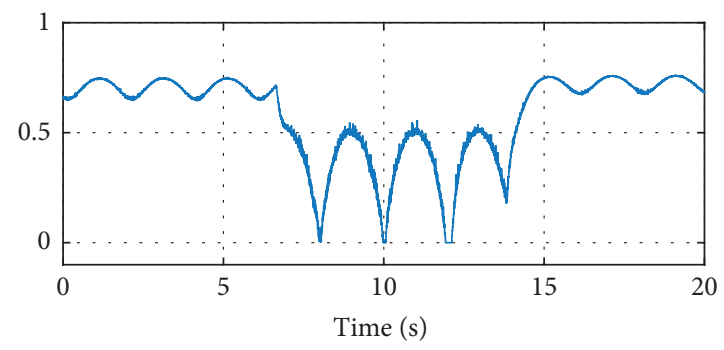

(c)

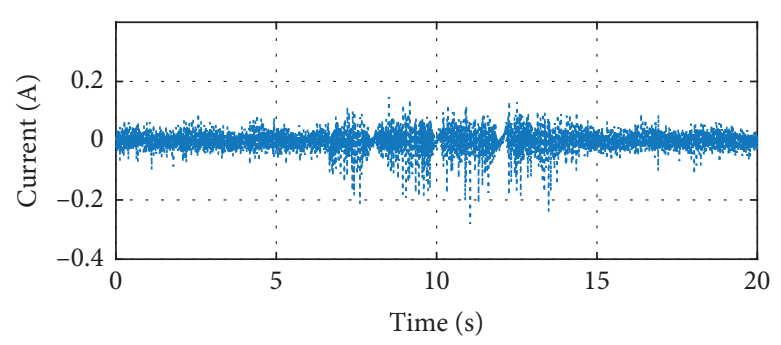

(b)

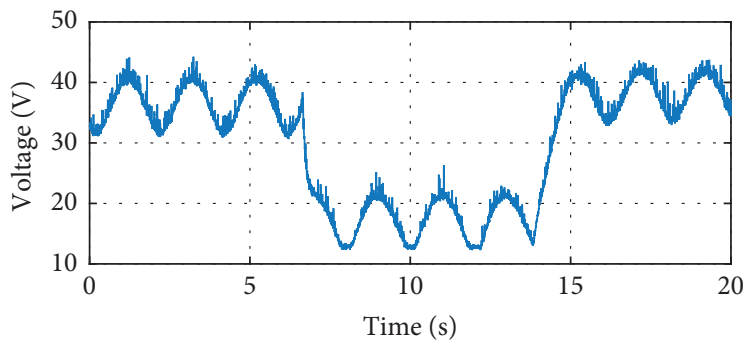

(d)

FIGURE 26: Boost converter response to path following with the SSTA controller. (a) Desired current and measured current. (b) Error. (c) Control action. (d) Output voltage.

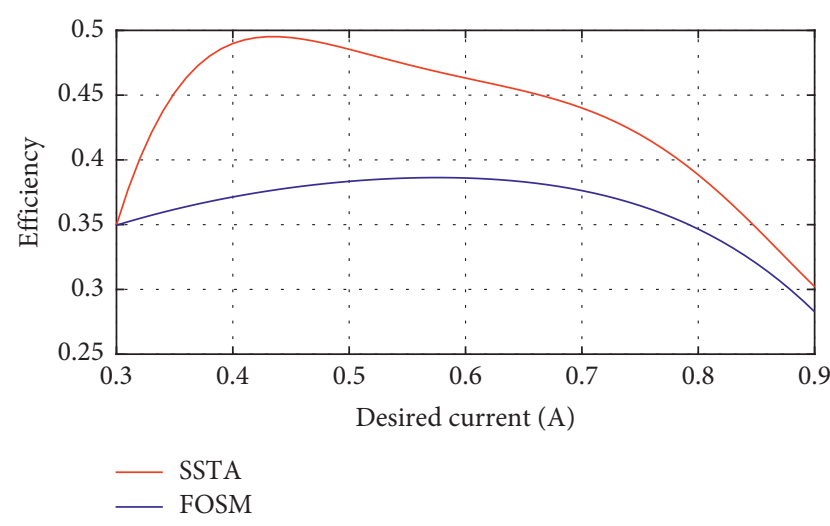

FIgURE 27: $\eta-i^{*}$ characteristic curves of the SSTA and FOSM controllers.

\section{Conclusion}

An SSTA controller is designed for a boost converter. This methodology can be applied to other power converters. The controller is capable to track in finite-time a desired current profile, while it compensates, in the same manner, bounded Lipschitz uncertainties/perturbations by generating a bounded continuous control signal. The continuous control signal is applied to the boost converter by using $\Sigma \Delta M$. The application of a continuous sliding mode controller in a power converter diminishes the energy of the error signal in comparison with the one presented with a FOSM controller. The proposed controller is embedded in a development card and applied to a real boost converter, showing the applicability of the proposed approach.

\section{Data Availability}

The data used to support this study are included within this article.

\section{Conflicts of Interest}

The authors declare that there are no conflicts of interest regarding the publication of this paper.

\section{Acknowledgments}

In memory of Oscar Villafuerte-Segura, my brother, my partner, and unconditional friend. I will never forget you, Andrés A. Galván-Navarro, my beloved father, teacher, guide, and dearest friend; you will always be in my heart. This work was supported in part by the Secretaría de Investigación $\mathrm{y}$ Posgrado of the Instituto Politécnico Nacional (20200687, 20202256, and 20200143) and the CONACyT scholarship (no. 958158).

\section{References}

[1] J.-S. Lai and D. J. Nelson, "Energy management power converters in hybrid electric and fuel cell vehicles," Proceedings of the IEEE, vol. 95, no. 4, pp. 766-777, 2007.

[2] B. Ge, Q. Lei, F. Z. Peng, D. Song, Y. Liu, and A. R. Haitham, "An effective PV power generation control system using Quasi- $Z$ source inverter with battery," in Proceedings of the 2011 IEEE Energy Conversion Congress and Exposition, Phoenix, AZ, USA, September 2011.

[3] M. Habib, A. A. Ladjici, and E. Bollin, "Finite set MPC control of two level inverter for PV/battery grid-connected system," in 
Proceedings of the 2017 6th International Conference on Systems and Control (ICSC), Batna, Algeria, May 2017.

[4] A. Sahli, F. Krim, A. Laib, and B. Talbi, "Energy management and power quality enhancement in grid-tied single-phase PV system using modified PUC converter," IET Renewable Power Generation, vol. 13, no. 14, pp. 2512-2521, 2019.

[5] Y. Zhou, H. Obeid, S. Laghrouche, M. Hilairet, and A. Djerdir, "Disturbance rejection control strategy of hybrid battery/ super capacitors power system based on a single converter," in Proceedings of the 2019 8th International Conference on Renewable Energy Research and Applications (ICRERA), Brasov, Romania, November 2019.

[6] S. A. Gorji, H. G. Sahebi, M. Ektesabi, and A. B. Rad, "Topologies and control schemes of bidirectional DC-DC power converters: an overview," IEEE Access, vol. 7, no. 1, pp. 117997-118019, 2019.

[7] S. Hajiaghasi, A. Salemnia, and M. Hamzeh, "Hybrid energy storage system for microgrids applications: a review," Journal of Energy Storage, vol. 21, no. 1, pp. 543-570, 2019.

[8] H. El Fadil and F. Giri, "Backstepping based control of PWM DC-DC boost power converters," in Proceedings of the 2007 IEEE International Symposium on Industrial Electronics, Vigo, Spain, June 2007.

[9] M.-G. Kim, "Proportional-integral (PI) compensator design of duty-cycle-controlled buck LED driver," IEEE Transactions on Power Electronics, vol. 30, no. 7, pp. 3852-3859, 2015.

[10] A. Kuperman, "Proportional-resonant current controllers design based on desired transient performance," IEEE Transactions on Power Electronics, vol. 30, no. 10, pp. 53415345, 2015.

[11] S. Padmanaban, G. Grandi, F. Blaabjerg, P. Wheeler, P. Siano, and M. Hammami, "A comprehensive analysis and hardware implementation of control strategies for high output voltage DC-DC boost power converter," International Journal of Computational Intelligence Systems, vol. 10, no. 1, pp. 140-152, 2017.

[12] A. Mushi, S. Nagai, H. Obara, and A. Kawamura, "Fast and robust nonlinear deadbeat current control for boost converter," IEEJ Journal of Industry Applications, vol. 6, no. 5, pp. 311-319, 2017.

[13] K. Shen, J. Feng, and J. Zhang, "Finite control set model predictive control with feedback correction for power converters," CES Transactions on Electrical Machines and Systems, vol. 2, no. 3, pp. 312-319, 2018.

[14] S. Pang, B. Nahid-Mobarakeh, S. Pierfederici et al., "Interconnection and damping assignment passivity-based control applied to on-board DC-DC power converter system supplying constant power load," IEEE Transactions on Industry Applications, vol. 55, no. 6, pp. 6476-6485, 2019.

[15] H. W. Choi, S. M. Kim, J. Kim, Y. Cho, and K. B. Lee, "Deadbeat predictive direct power control of interleaved buck converter-based fast battery chargers for electric vehicles," Journal of Power Electronics, vol. 20, no. 1, pp. 1162-1171, 2020.

[16] G. Rigatos, P. Siano, and M. Sayed-Mouchaweh, "Adaptive neurofuzzy $H$-infinity control of DC-DC voltage converters," Neural Computing and Applications, vol. 32, no. 1, pp. 2507-2520, 2020.

[17] H. Sira-Ramírez and R. Silva-Ortigoza, Control Design Techniques in Power Electronics Devices, Springer-Verlag London, London, UK, 1 edition, 2006.

[18] V. I. Utkin, J. Guldner, and J. Shi, Sliding Mode Control in Electro-Mechanical Systems, CRC Press, Boca Raton, FL, USA, 2009.
[19] Z. Chen, "Double loop control of buck-boost converters for wide range of load resistance and reference voltage," IET Control Theory \& Applications, vol. 6, no. 7, pp. 900-910, 2012.

[20] Y. M. Alsmadi, V. Utkin, M. A. Haj-ahmed, and L. Xu, "Sliding mode control of power converters: DC/DC converters," International Journal of Control, vol. 91, no. 11, pp. 2472-2493, 2018.

[21] J. A. V. Formenti and G. R. Elder, "Method and apparatus for controlling charge balance among cells while charging a battery array," US. Patent 6700350B2, 2004.

[22] C. W. Tan, T. C. Green, and C. A. Hernandez-Aramburo, “An improved maximum power point tracking algorithm with current-mode control for photovoltaic applications," in Proceedings of the 2005 International Conference on Power Electronics and Drives Systems, Kuala Lumpur, Malaysia, November 2005.

[23] M. Aime, G. Gateau, and T. A. Meynard, "Implementation of a peak-current-control algorithm within a field-programmable gate array," IEEE Transactions on Industrial Electronics, vol. 54, no. 1, pp. 406-418, 2007.

[24] Q. Huang, X. Zou, D. Zhu, and Y. Kang, "Scaled current tracking control for doubly fed induction generator to ridethrough serious grid faults," IEEE Transactions on Power Electronics, vol. 31, no. 3, pp. 2150-2165, 2016.

[25] N. Vafamand, A. Khayatian, and M. H. Khooban, "Stabilisation and transient performance improvement of DC MGs with CPLs: non-linear reset control approach," IET Generation, Transmission \& Distribution, vol. 13, no. 14, pp. 31693176, 2019.

[26] N. Vafamand, S. Yousefizadeh, M. H. Khooban, J. D. Bendtsen, and T. Dragicevic, "Adaptive TS fuzzy-based MPC for DC microgrids with dynamic CPLs: nonlinear power observer approach," IEEE Systems Journal, vol. 13, no. 3, pp. 3203-3210, 2019.

[27] J. Wu and Y. Lu, "Adaptive backstepping sliding mode control for boost converter with constant power load," IEEE Access, vol. 7, no. 1, pp. 50797-50807, 2019.

[28] Y. Shtessel, C. Edwards, L. Fridman, and A. Levant, Sliding Mode Control and Observation, Birkhäuser, New York, NY, USA, 1 edition, 2014.

[29] V. Utkin, "Sliding mode control of DC/DC converters," Journal of the Franklin Institute, vol. 350, no. 8, pp. 2146-2165, 2013.

[30] A. Levant, "Sliding order and sliding accuracy in sliding mode control," International Journal of Control, vol. 58, no. 6, pp. 1247-1263, 1993.

[31] R. Seeber and M. Horn, "Stability proof for a well-established super-twisting parameter setting," Automatica, vol. 84, no. 1, pp. 241-243, 2017.

[32] A. Levant, "Chattering analysis," IEEE Transactions on Automatic Control, vol. 55, no. 6, pp. 1380-1389, 2010.

[33] U. P. Ventura and L. Fridman, "Chattering measurement in SMC and HOSMC," in Proceedings of the 2016 14th International Workshop on Variable Structure Systems (VSS), Nanjing, China, June 2016.

[34] I. Castillo, M. Steinberger, L. Fridman, J. Moreno, and M. Horn, "Saturated super-twisting algorithm based on perturbation estimator," in Proceedings of the 2016 IEEE 55th Conference on Decision and Control (CDC), Las Vegas, NV, USA, December 2016.

[35] R. Seeber and M. Horn, "Guaranteeing disturbance rejection and control signal continuity for the saturated super-twisting algorithm," IEEE Control Systems Letters, vol. 3, no. 3, pp. 715-720, 2019. 
[36] S. Oucheriah, L. Guo, "PWM-Based adaptive sliding-mode control for boost DC-DC convertersy," IEEE Transactions on Industrial Electronics, vol. 60, no. 8, pp. 3291-3294, 2013.

[37] A. Goudarzian, A. Khosravi, and H. A. Raeisi, "Optimized sliding mode current controller for power converters with non-minimum phase nature," Journal of the Franklin Institute, vol. 356, no. 15, pp. 8569-8594, 2019.

[38] H. Sira-Ramírez, Sliding Mode Control: The Delta-Sigma Modulation Approach, Birkhäuser Basel, Basel, Switzerland, 1 edition, 2015

[39] J. D. Reiss, "Understanding sigma-delta modulation: the solved and unsolved issues," Journal of the Audio Engineering Society, vol. 56, no. 1/2, pp. 49-64, 2008.

[40] J. M. De La Rosa, "Sigma-delta modulators: tutorial overview, design guide, and state-of-the-art survey," IEEE Transactions on Circuits and Systems I: Regular Papers, vol. 58, no. 1, pp. 1-21, 2011.

[41] O. Alkin, Signals and Systems: A MATLAB Integrated Approach, CRC Press, Inc., Boca Raton, FL, USA, 2014.

[42] B. Lehman and Z. Mihajlovic, "Output ripple analysis of switching DC-DC converters," in Proceedings of the PESC97. Record 28th Annual IEEE Power Electronics Specialists Conference. Formerly Power Conditioning Specialists Conference 1970-71. Power Processing and Electronic Specialists Conference 1972, Saint Louis, MO, USA, June 1997.

[43] O. López-Santos, H. Valderrama-Blavi, G. García, D. O. Mercuri, and L. Martínez-Salamero, "Efficiency analysis of a sliding-mode controlled quadratic boost converter," IET Power Electronics, vol. 6, no. 2, pp. 364-373, 2013. 